\title{
Palladium on carbon-catalyzed -alkylation of ketones with alcohols as electrophiles: Scope and mechanism
}

\author{
Bennedsen, Niklas R.; Mortensen, Rasmus L.; Kramer, Søren; Kegnæs, Søren
}

Published in:

Journal of Catalysis

Link to article, DOI:

10.1016/j.jcat.2019.01.034

Publication date:

2019

Document Version

Peer reviewed version

Link back to DTU Orbit

Citation (APA):

Bennedsen, N. R., Mortensen, R. L., Kramer, S., \& Kegnæs, S. (2019). Palladium on carbon-catalyzed -

alkylation of ketones with alcohols as electrophiles: Scope and mechanism. Journal of Catalysis, 371, 153-160. https://doi.org/10.1016/j.jcat.2019.01.034

\section{General rights}

Copyright and moral rights for the publications made accessible in the public portal are retained by the authors and/or other copyright owners and it is a condition of accessing publications that users recognise and abide by the legal requirements associated with these rights.

- Users may download and print one copy of any publication from the public portal for the purpose of private study or research.

- You may not further distribute the material or use it for any profit-making activity or commercial gain

- You may freely distribute the URL identifying the publication in the public portal 


\section{Palladium on Carbon-Catalyzed $\alpha$-Alkylation of Ketones}

\section{2 with Alcohols as Electrophiles: Scope and Mechanism}

3 Niklas R. Bennedsen, Rasmus L. Mortensen, Søren Kramer*, Søren Kegnæs*

4 Department of Chemistry, Technical University of Denmark, 2800 Kgs. Lyngby, Denmark

5 E-mail addresses: sokr@kemi.dtu.dk (S. Kramer), skk@kemi.dtu.dk (S. Kegnæs).

7 Abstract:

8 The $\alpha$-alkylation of ketones with alcohols represents a green strategy for the formation of crucial

9 carbon-carbon bonds since it only produces water as byproduct. In terms of reaction mechanism,

10 the evidence for homogeneous catalysis supports a catalytic hydrogen-borrowing pathway;

11 however, the reaction mechanism has not been investigated for heterogeneous $\mathrm{Pd} / \mathrm{C}$ catalysts. Here,

12 we report an improved method for $\alpha$-alkylation of ketones with alcohols using commercially

13 available $\mathrm{Pd} / \mathrm{C}$, ubiquitous in organic synthesis labs, as catalyst. The reaction conditions are mild

14 compared to state-of-the-art for both homo- and heterogeneous catalysts, and the developed

15 conditions produces quantitative yields for most ketones and alcohols. A hot filtration experiment

16 and recycling of the catalyst supports the heterogeneous nature of catalysis. Importantly, the

17 reaction mechanism is studied for the first time by a combination of stoichiometric experiments and

18 kinetic analyses by in-situ IR (React-IR).

19 Keywords: Pd/C Catalysis, Reaction Mechanism, $\alpha$-Alkylation, Heterogeneous Catalysis, In-situ

20 IR, Kinetics, C-C bond formation. 
22 Methods for facile carbon-carbon bond formation are crucial for the synthesis of organic molecules

23 such as pharmaceuticals, agrochemicals, and functional materials.[1-4] Accordingly, the formation

24 of a new $\mathrm{C}\left(\mathrm{sp}^{3}\right)-\mathrm{C}\left(\mathrm{sp}^{3}\right)$ bond to the $\alpha$-carbon of carbonyl compounds, termed $\alpha$-alkylation, is an

25 important transformation that has received considerable attention.[5-10] Conventional methods for

$26 \alpha$-alkylation reactions often have problems with undesired waste, e.g. salts from alkyl halides, and

27 require strong metallic bases and cryogenic temperatures. These aspects limit the industrial

28 implementation and decrease the atom efficiency and sustainability of the methodologies.[11,12]

29 Recently, a different strategy where alcohols are used as masked electrophiles, leading to water as

30 the only byproduct, has attracted attention due to its potential as a greener alternative.[13-19] A

31 variety of transition-metals has been implemented as catalysts for the $\alpha$-alkylation of ketones with

32 alcohols in both homogeneous[20-30] and heterogeneous systems[31-41]. Typically, reaction

33 temperatures above $100{ }^{\circ} \mathrm{C}$ and $1-2$ mol\% catalyst loadings are required.

34 For homogeneous systems, the reaction mechanism for $\alpha$-alkylation of ketones with alcohols

35 has been thoroughly examined and the general consensus is that the reactions proceed through a

36 hydrogen-borrowing pathway (Figure 1).[19,23,26,30,34,42] The reaction is initiated by

37 dehydrogenation of the alcohol forming the corresponding aldehyde, thus activating it as an

38 electrophile. Next, aldol condensation, which is typically catalyzed by addition of base, reacts the

39 produced aldehyde and the ketone affording an $\alpha, \beta$-unsaturated ketone. Finally, the $\mathrm{C}-\mathrm{C}$ double

40 bond is hydrogenated by the hydrogen originally removed from the alcohol, hence the term

41 "hydrogen-borrowing”.

42 In contrast to the homogeneous reactions, limited mechanistic evidence has been accumulated

43 for $\alpha$-alkylation of ketones with alcohols using heterogeneous catalysis.[37,39,41] In particular, no 
44 thorough mechanistic investigation including kinetics has been performed on $\alpha$-alkylation of

45 ketones with alcohols using palladium on carbon catalysis. A reaction pathway similar to

46 homogeneous catalysis is tempting to propose; however, it cannot always be assumed that the

47 pathways with homogeneous and heterogeneous catalysts are the same.[43,44] A better

48 understanding of the operating pathways is pivotal for advancement of the field and rational design 49 of future reactions.

50

51

52

53

54 investigation, where commercially available $\mathrm{Pd} / \mathrm{C}$ is used as catalyst for $\alpha$-alkylation of ketones

55 with alcohols.[31] The catalytic system used for the reaction between acetophenone and benzyl

56 alcohol (2 equiv) was comprised of $5 \mathrm{~mol} \% \mathrm{Pd} / \mathrm{C}, 3$ equivalents $\mathrm{KOH}$, and 4 equivalents 1 -decene

57 in dioxane at $100{ }^{\circ} \mathrm{C}$ for $20 \mathrm{~h}$ and afforded $66 \%$ yield of the corresponding 1,3-diphenylpropan-1-

58 one. Albeit, the use of a commercially available catalyst which is ubiquitous in organic synthesis

59 laboratories is highly convenient, the moderate yield, high catalyst loading, and need for strong base 
60 and an additive warrant improvements. Furthermore, no investigation of the reaction mechanism

61 was performed.

62 Herein, we report a mechanistic investigation of a significantly improved and simplified method

63 for $\alpha$-alkylation of acetophenones with alcohols using commercially available $\mathrm{Pd} / \mathrm{C}$ as the catalyst.

64 The individual reaction steps are examined by stoichiometric studies and reaction kinetics is

65 thoroughly investigated by in-situ IR measurements. In addition, the catalyst material is studied by

66 TEM and XPS, and the nature of catalysis is examined by hot filtration and recycling experiments.

67 Finally, based on the mechanistic investigation, a rational solution for future optimization of $\alpha$ -

68 alkylations is suggested.

69

70

71 After an optimization of the reaction conditions on the reaction between acetophenone and benzyl

72 alcohol, the desired product was obtained in a quantitative yield (Table 1, entry 1). The optimized

73 reaction conditions use $1 \mathrm{~mol} \% \mathrm{Pd} / \mathrm{C}, 1.1$ equivalents benzyl alcohol, and 1.5 equivalents of $\mathrm{K}_{3} \mathrm{PO}_{4}$

74 in toluene at $80^{\circ} \mathrm{C}$ for 6 hours. The reaction conditions are slightly milder, but otherwise very

75 similar to those recently reported for a custom-made palladium on carbon catalyst.[38] Control

76 experiments showed that no product is formed in the absence of $\mathrm{Pd} / \mathrm{C}$ and that activated carbon

77 without palladium leads to highly unselective conversion (entries 2-3). The weight percentage

78 loading of palladium on the carbon does not influence the reaction outcome (entry 4). However, the

79 reaction is sensitive to air and choice of base (entries 5-9). Finally, variations to the $\mathrm{K}_{3} \mathrm{PO}_{4}$

80 equivalents, headspace, and concentration were undertaken to ensure that changes to these

81 parameters during a mechanistic investigation was not detrimental to the reaction outcome (entries 82 10-17). 
Table 1. Influence of various reaction parameters on the reaction outcome.

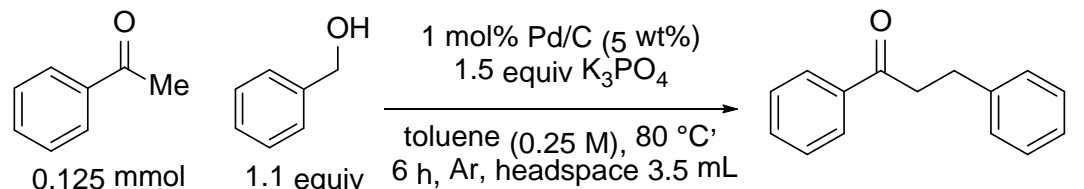

\begin{tabular}{llll}
\hline Entry & Modifications & Conversion (\%) & Yield (\%) $^{\mathrm{a}}$ \\
\hline 1 & - & 100 & 100 \\
2 & no catalyst & 6 & 0 \\
3 & activated carbon & $43^{\mathrm{b}}$ & $3^{\mathrm{b}}$ \\
4 & $10 \mathrm{wt} \% \mathrm{Pd} / \mathrm{C}$ & 100 & 100 \\
5 & in air & 32 & 7 \\
6 & $\mathrm{~K}_{2} \mathrm{CO}_{3}$ & 0 & 0 \\
7 & $\mathrm{Li}_{2} \mathrm{CO}_{3}$ & 0 & 0 \\
8 & $\mathrm{Cs}_{2} \mathrm{CO}_{3}$ & 66 & 66 \\
9 & $\mathrm{Et}_{3} \mathrm{~N}$ & 0 & 0 \\
10 & 1.0 equiv $\mathrm{K}_{3} \mathrm{PO}_{4}$ & 100 & 100 \\
11 & 2.0 equiv $\mathrm{KO}_{3} \mathrm{PO}_{4}$ & 100 & 100 \\
12 & headspace $3.0 \mathrm{~mL}$ & 100 & 100 \\
13 & headspace $2.5 \mathrm{~mL}$ & 99 & 99 \\
14 & headspace $2.0 \mathrm{~mL}$ & 97 & 97 \\
15 & $0.125 \mathrm{M}$ & 100 & 100 \\
16 & $0.50 \mathrm{M}$ & 100 & 100 \\
17 & $1.0 \mathrm{M}$ & 100 & 100 \\
\hline
\end{tabular}

a Based on ${ }^{1} \mathrm{H}$ NMR using 0.5 equivalents of dibenzyl ether as standard.

${ }^{\mathrm{b}}$ Reaction time was 24 hours.

Having established optimized reaction conditions, the generality of the transformation was assessed by a substrate scope investigation. To ensure one general procedure for all substrates, the reaction time was increased to 24 hours. First, acetophenone was reacted with various alcohols (Table 2).

91 Derivatives of benzyl alcohol bearing electron-withdrawing or -donating groups in the para-

92 position (Me, $\mathrm{OMe}, \mathrm{CF}_{3}$, and $\mathrm{F}$ ) provided excellent product yields (entries 1-5). In contrast, the use

93 of a secondary benzylic alcohol did not lead to any product formation (entry 6), neither did a

94 secondary aliphatic alcohol, pentan-3-ol (not shown). Although primary aliphatic alcohols reacted

95 more sluggishly than benzylic alcohols, an increase in temperature from $80^{\circ} \mathrm{C}$ to $100^{\circ} \mathrm{C}$ led to good

96 yields of the corresponding ketone for both heptanol and propanol, respectively (entries 7-8). 
Table 2. Substrate scope with respect to the alcohol.

\begin{tabular}{|c|c|c|c|c|}
\hline Entry & $\mathrm{R}^{1}$ & $\mathrm{R}^{2}$ & Conversion (\%) & Yield (\%) $^{\mathrm{a}}$ \\
\hline 1 & $\mathrm{H}$ & $\mathrm{H}$ & 100 & 100 \\
\hline 2 & $\mathrm{Me}$ & $\mathrm{H}$ & 100 & 100 \\
\hline 3 & $\mathrm{MeO}$ & $\mathrm{H}$ & 100 & 100 \\
\hline 4 & F & $\mathrm{H}$ & 100 & 100 \\
\hline 5 & $\mathrm{CF}_{3}$ & $\mathrm{H}$ & 98 & 98 \\
\hline 6 & $\mathrm{~F}$ & $\mathrm{Me}$ & 0 & 0 \\
\hline 7 & & & 72 & $72^{\mathrm{b}}$ \\
\hline 8 & 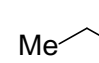 & & 73 & $73^{\mathrm{b}}$ \\
\hline
\end{tabular}

${ }^{a}$ Based on ${ }^{1} \mathrm{H}$ NMR using 0.5 equivalents of dibenzyl ether as standard.

${ }^{\mathrm{b}}$ Reaction temperature was $100^{\circ} \mathrm{C}$.

Next, a series of acetophenone derivatives were reacted with benzyl alcohol (Table 3).

101 Again, substrates bearing substituents ranging from very electron-donating to very electron-

102 withdrawing (Me, $\mathrm{OMe}, \mathrm{CF}_{3}$, and $\mathrm{F}$ ) provided excellent yields and selectivity towards the ketone

103 product (entries $1-5$ ). Substitution on the $\alpha$-carbon of acetophenone decreased the activity but

104 maintained high selectivity towards the ketone product (entry 6). Sterical hindrance in the ortho-

105 position of the acetophenone was well-tolerated (entry 7). Interestingly, under the same reaction

106 conditions, two aliphatic ketones also smoothly underwent $\alpha$-alkylation with excellent selectivity

107 for the least substituted $\alpha$-carbon (entries 8-9). 
Table 3. Substrate scope with respect to the ketone.

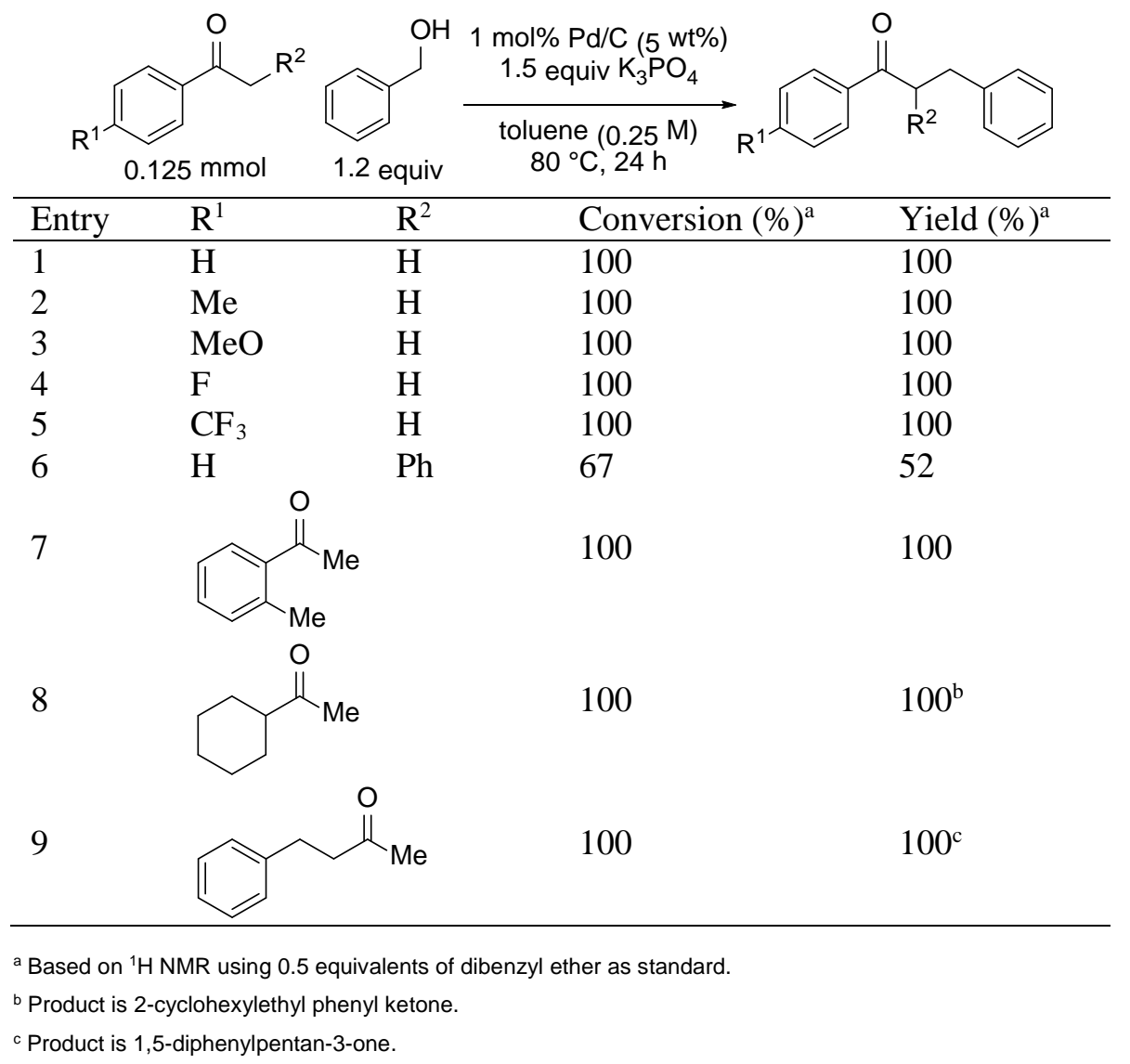

113

\section{3) Recycling and Heterogeneity}

115 With regard to the nature of the hydrogen-borrowing catalysis, there are two possibilities: 1)

116 heterogeneous catalysis by palladium nanoparticles or 2) leaching of catalytically active

117 homogeneous species.[45,46] To distinguish between these possibilities, a hot filtration experiment

118 was performed (Scheme 1). In the experiment, inhibition of the catalytic activity occurred when the

119 solid catalyst was removed from the reaction mixture despite the addition of fresh $\mathrm{K}_{3} \mathrm{PO}_{4}(1.5$ 
121 hydrogen-borrowing catalysis. Accordingly, the developed catalytic system is appropriate for a

122 reaction mechanism study of heterogeneous Pd/C-catalyzed $\alpha$-alkylation.

123

124 alcohol.

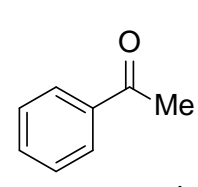

$0.25 \mathrm{mmol}$

$1 \mathrm{~h}: 35 \%$

6 h: $31 \%$

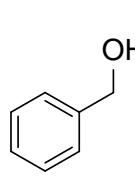

1.2 equiv

$38 \%$

$37 \%$
1) $1 \mathrm{~mol} \% \mathrm{Pd} / \mathrm{C}(5 \mathrm{wt} \%)$ 1.5 equiv $\mathrm{K}_{3} \mathrm{PO}_{4}$ toluene $(0.25 \mathrm{M}), 80^{\circ} \mathrm{C}, 1 \mathrm{~h}$

2) Filtration while hot 1.5 equiv $\mathrm{K}_{3} \mathrm{PO}_{4}, 80^{\circ} \mathrm{C}, 5 \mathrm{~h}$

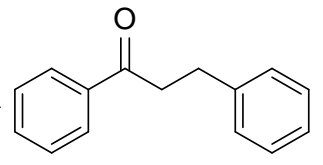

$65 \%$

$66 \%$

131 for procedure). Throughout all consecutive reactions, excellent selectivity was maintained, but a

132 decrease in activity was observed at the fourth recycle (from $96 \%$ to $60 \%$ ). The TEM images of the

133 fresh $\mathrm{Pd} / \mathrm{C}$ catalyst and the $\mathrm{Pd} / \mathrm{C}$ catalysts which had been recycled four times appeared similar.

134 Both contain Pd nanoparticles with a size of 2-20 nm with a tendency of fewer smaller particles for

135 the recycled compared to the fresh catalyst but few to none larger agglomerates (Figure 2;

136 additional images in supporting information). Accordingly, particle agglomeration is unlikely to

137 cause catalyst deactivation. The reaction liquid was analyzed by ICP-OES and the palladium

138 content in the reaction liquid was equal or below the blank suggesting that palladium does not leach under our reaction conditions (see supporting information for procedure). 
Table 4. Recycling of the commercial Pd/C catalyst.

\begin{tabular}{llll}
\hline & \\
\hline Entry & Number of recycles & Conversion $(\%)^{\mathrm{b}}$ & Selectivity (\%) $)^{\mathrm{b}}$ \\
\hline 1 & 0 & 100 & 100 \\
2 & 1 & 100 & 100 \\
3 & 2 & 100 & 100 \\
4 & 3 & 96 & 100 \\
5 & 4 & 60 & 100 \\
\hline
\end{tabular}

142

143

144

145

146

a Recycling was performed by extracting the reaction mixture with toluene

to remove organic residues from the catalyst. 1.5 equiv fresh $\mathrm{K}_{3} \mathrm{PO}_{4}$ was

added together with a new batch of substrates.

${ }^{\mathrm{b}}$ Based on ${ }^{1} \mathrm{H}$ NMR using 0.5 equivalents of dibenzyl ether as standard.

XPS analysis of palladium (3d) for the fresh and recycled catalysts was performed (Figure 3). The spectrum of palladium for the fresh catalyst indicated the presence of two species with binding energies consistent with $\mathrm{Pd}$ and $\mathrm{PdO}$ at $335.4 \mathrm{eV}$ and $336.8 \mathrm{eV}$ for the $3 \mathrm{~d}_{5 / 2}$ transition, respectively (Figure 3, left).[47] The same was observed for the $3 \mathrm{~d}_{3 / 2}$ signal at approximately 340 and $342 \mathrm{eV}$. However, the signals for the PdO species were suppressed strongly and Pd was primarily observed for the recycled catalyst. This observation indicates that PdO was reduced under the reaction conditions, possibly by hydrogen released from benzyl alcohol. The composition of the carbon from the catalyst did not show any difference between the fresh and recycled catalyst (Figure 3, right). Based on the observation made from XPS, TEM, and ICP, we see a slight change in nanoparticle composition and size, and no palladium is leached during the reaction. However, the effect of change in composition and size of the nanoparticles relative to the deactivation during the recycle study is still only speculative. 


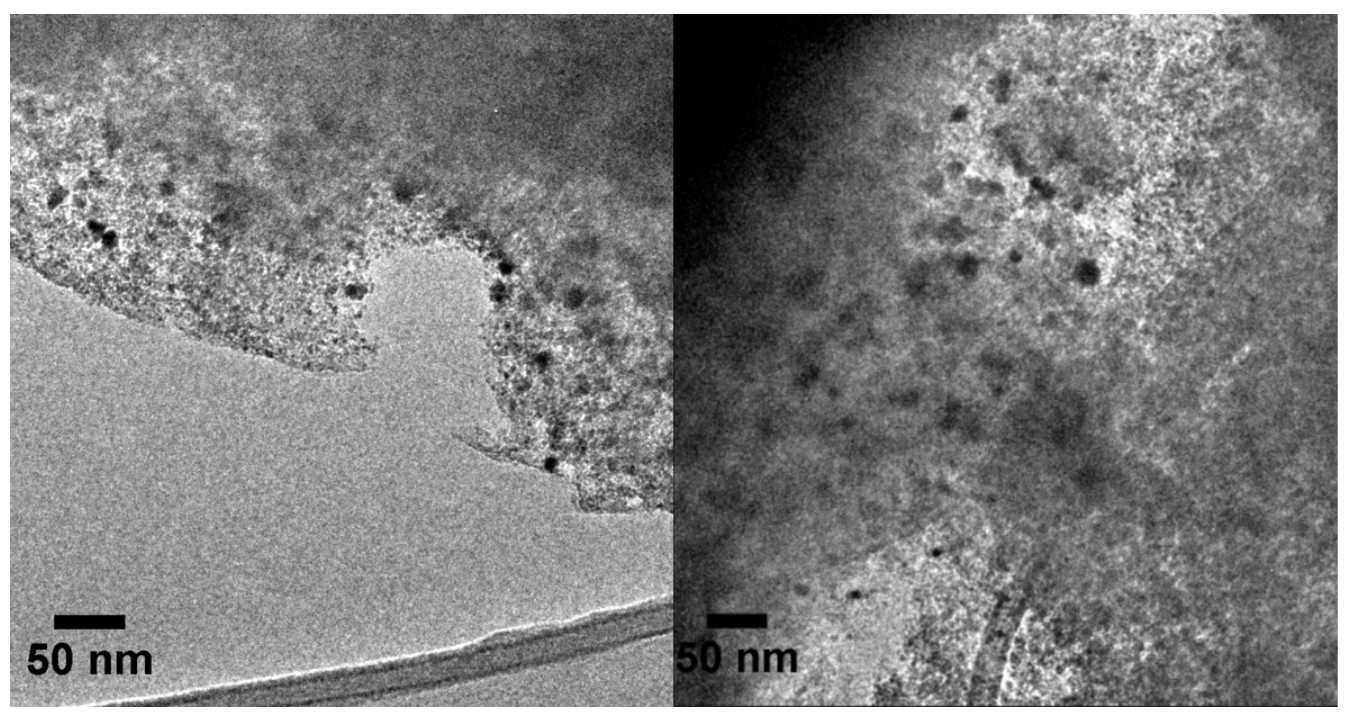

Figure 2. (Left) TEM image of unused Pd/C catalyst. (Right) TEM image of recycled Pd/C

that have been used for five consecutive reactions.

162
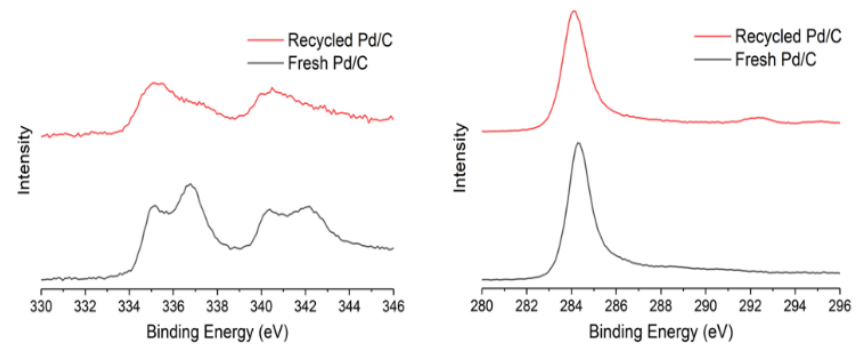

Figure 3. XPS analysis of the fresh Pd/C catalyst and the recycled Pd/C catalyst. (Left) Pd

1643 d analysis and (right) C 1s analysis of both the fresh and the recycled catalyst.

167 Finally, we sought to identify the reaction pathway of the developed heterogeneous catalysis

168 system. Potentially, a reaction mechanism similar to the one elucidated for the homogeneous

169 counterparts could be operating (Figure 1). Accordingly, a series of experiments were performed to 170 establish the feasibility of the individual steps (Scheme 2). Initially, it was demonstrated that Pd/C 
171 is capable of dehydrogenating benzyl alcohol forming benzaldehyde, independent of the presence of

$172 \mathrm{~K}_{3} \mathrm{PO}_{4}$ (Scheme 2a). Next, the quantitative formation of chalcone from acetophenone and

173 benzaldehyde was established both under the standard catalytic conditions and in the absence of

$174 \mathrm{Pd} / \mathrm{C}$ (Scheme 2b). Notably, the chalcone is not reduced due to the lack of a hydrogen donor under

175 these conditions. However, subjecting the chalcone to the reaction conditions in the presence of

176 benzyl alcohol as hydrogen donor leads to facile reduction of the $\mathrm{C}-\mathrm{C}$ double bond and oxidation of

177 benzyl alcohol (Scheme 2c). Finally, a cross-over experiment between acetophenone, benzaldehyde,

178 and $\mathrm{CF}_{3}$-labelled benzyl alcohol demonstrated that both the benzylic alcohol substrate and

179 benzaldehyde can form product under the standard catalytic conditions (Scheme 2d). In addition, 180 the observation of significant amounts of unlabeled benzyl alcohol indicates that the alcohol 181 dehydrogenation is reversible. Overall, these results are consistent with the hydrogen-borrowing 182 mechanism illustrated in Figure 1, thus such a reaction mechanism is also likely to be operating 183 under the heterogeneous catalytic conditions developed here.

Scheme 2. Stoichiometric experiments conducted with Pd/C catalyst. a) Test for alcohol dehydrogenation. b) Chalcone formation from acetophenone and benzaldehyde under standard reaction conditions. c) Chalcone hydrogenation using benzyl alcohol as hydrogen donor. d) Crossover experiment demonstrating product formation from both a benzylic alcohol and aldehyde under the reaction conditions. A control experiment demonstrated that the use of 2.4 equiv benzyl alcohol under the normal reaction conditions also provides quantitative yield. For all reactions, the yields

191 were determined by ${ }^{1} \mathrm{H}$ NMR using 0.5 equiv dibenzyl ether as standard. ${ }^{\text {a }}$ Conversion and yield 192 relative to added benzyl alcohol. 
a)

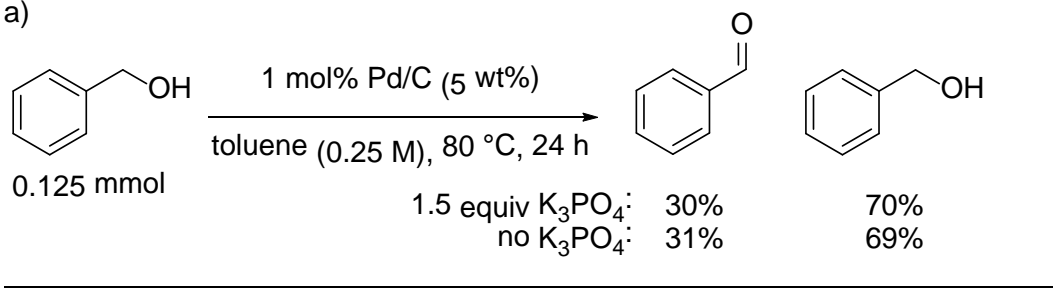

b)

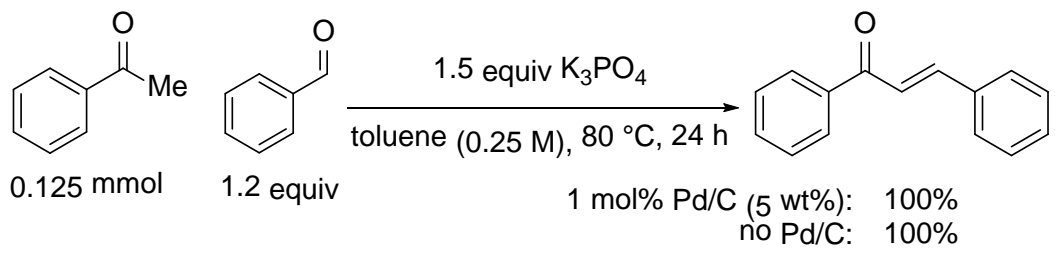

c)<smiles>O=C(/C=C/c1ccccc1)c1ccccc1</smiles>

$0.125 \mathrm{mmol}$

$1 \mathrm{~mol} \% \mathrm{Pd} / \mathrm{C}$ (5 wt\%) 1.5 equiv $\mathrm{K}_{3} \mathrm{PO}_{4}$<smiles>OCc1ccccc1</smiles>
toluene $(0.25 \mathrm{M}), 80^{\circ} \mathrm{C}, 24 \mathrm{~h}$<smiles>O=C(CCc1ccccc1)c1ccccc1</smiles>

1.2 equiv

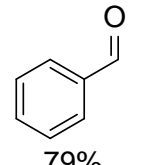

$\left(83 \%\right.$ conversion $\left.{ }^{\mathrm{a}}\right)$

d)<smiles>CC(=O)c1ccccc1</smiles><smiles>[R]C#[R16][14c]1cc([R])ccc1CCC(=O)c1ccccc1</smiles>

$125 \mathrm{mmol}$ $\mathrm{R}=\mathrm{CF}_{3}, 11 \%$<smiles>O=Cc1ccccc1</smiles>

$\left.1 \mathrm{~mol} \% \mathrm{Pd} / \mathrm{C}_{\text {(5 }} \mathrm{wt} \%\right)$
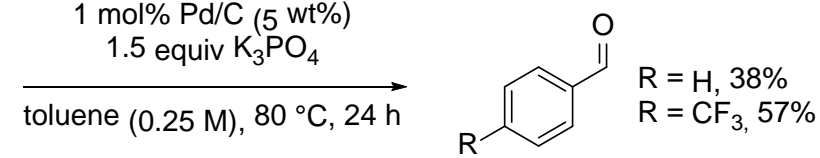

1.2 equiv

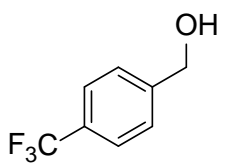

1.2 equiv

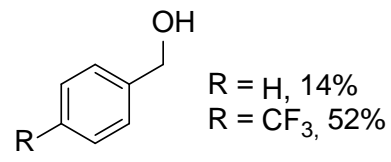


197 mmol scale version of the reaction between acetophenone and benzyl alcohol was monitored up to 198 90\% conversion (Figure 4). Supporting the stoichiometric experiments, both benzaldehyde and 199 chalcone were observed during the reaction, albeit in low concentrations. At 20 minutes and at 3 200 hours, the yields of the compounds detected by React-IR correspond to those detected by ${ }^{1} \mathrm{H}$ NMR.<smiles>CC(=O)c1ccccc1</smiles>

$1.25 \mathrm{mmol}$

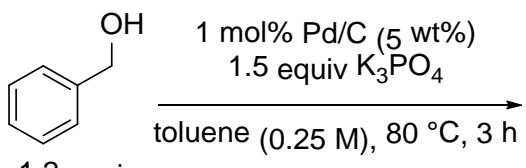

1.2 equiv<smiles>O=C(CCc1ccccc1)c1ccccc1</smiles>

202

203

204

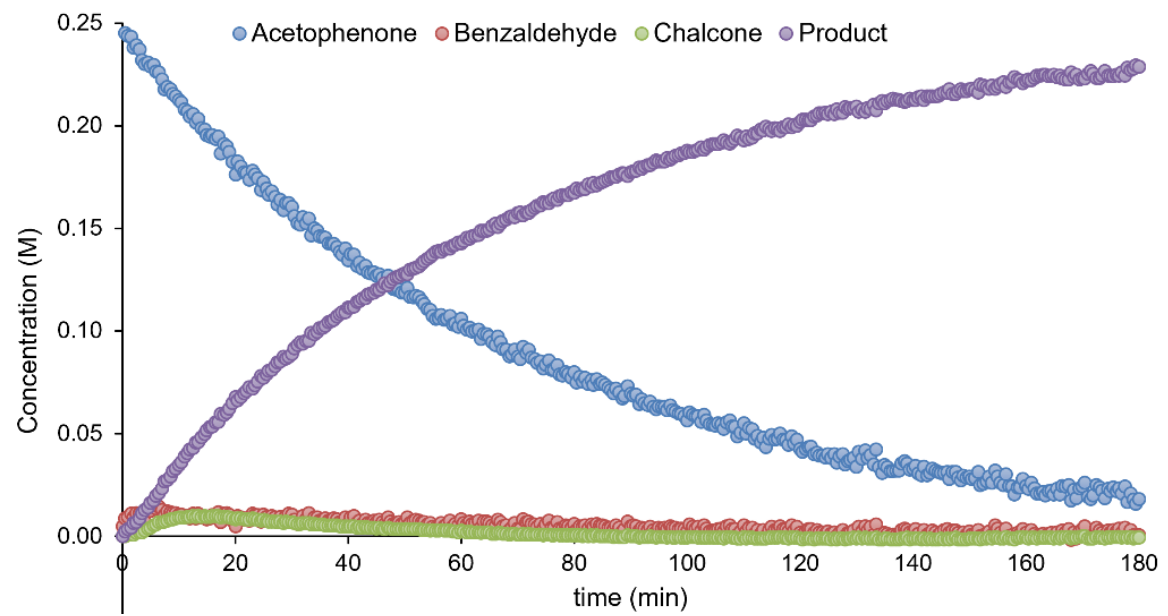

Figure 4. (top) Reaction conditions for React-IR. (bottom) Reaction profile monitored by React-IR.

Based on the reaction profile, the system appeared well-behaved and suitable for further kinetic analyses. The acetophenone consumption was chosen as a measure for the rate. First, a same excess experiment was performed (Figure 5a).[48] The almost perfect overlay of the time-adjusted same excess experiment indicates that there is no product inhibition or deactivation in the ratelimiting step. Interestingly, varying the Pd/C catalyst loading from 0.5 to $2.0 \mathrm{~mol} \%$ had no influence on the reaction rate (Figure 5b). Accordingly, the hydrogen-borrowing cycle does not contain the overall rate-limiting step, suggesting that the aldol condensation is rate-limiting. 
Plotting the acetophenone consumption in a first order plot produced a straight line up to

$21390 \%$ conversion (Figure 5c). Thus, the overall reaction order is either first order or at least pseudo-

214 first order. Variable time normalization analysis at two different acetophenone concentrations

215 clearly demonstrated a first order dependence on acetophenone concentration (Figure 5d; see

216 supporting information for fitting to other orders).[49] This is again consistent with the aldol

217 condensation being rate-limiting. However, unless deprotonation of acetophenone is rate-limiting,

218 generally, an overall second order reaction would be expected. Nonetheless, the detected, constant

219 steady-state concentration of benzaldehyde (Figure 4) could lead to an observed overall pseudo-first

220 order reaction, even if addition of the enolate to the aldehyde is rate-limiting. In either case, the rate

221 of the reaction only depends on the concentration of acetophenone with the experimental rate law

222 being: rate $=\mathrm{k}[$ ketone $]$.

223
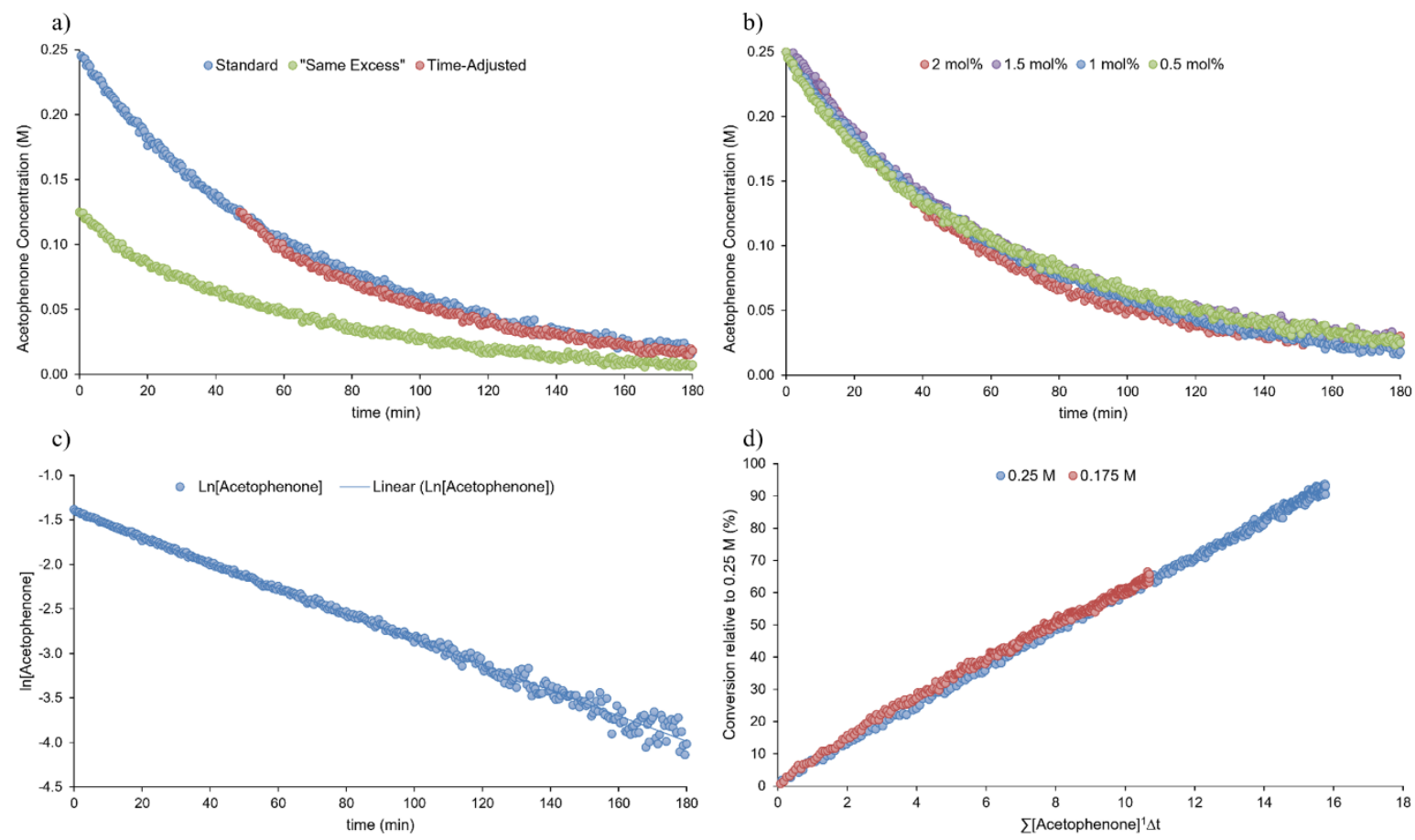
Figure 5. Reaction kinetics monitored by React-IR. a) Same excess experiment. b) Influence of catalyst loading on reaction rate. c) First order plot for determination of overall reaction order. d)

227 Variable time normalization analysis on two different acetophenone concentrations.

\section{3) Conclusions}

In summary, we have described an improved methodology for commercially available Pd/C-

catalyzed $\alpha$-alkylation of ketones with alcohols. The reaction conditions are mild, and most ketones and alcohols afford quantitative yields. The simple procedure and use of a catalyst which already can be found in any synthesis laboratory makes the method highly convenient and widespread use is mechanism analogous to homogeneous catalysis is supported. Surprisingly, the Pd/C-catalyzed hydrogen-borrowing cycle is very fast, even with only $0.5 \mathrm{~mol} \% \mathrm{Pd} / \mathrm{C}$, while the rate-limiting step was found to be the base-catalyzed aldol condensation. It is likely that the slow aldol condensation is the reason that elevated reaction temperatures are required for both homogeneous and heterogeneous $\alpha$-alkylation of ketones with alcohols. These observations indicate that it might be

241 possible to lower the reaction temperature in general for $\alpha$-alkylation of ketones with alcohols by

242 addition of improved catalysts for the aldol condensation step.

\section{Acknowledgments}

244 The authors are grateful for funding from the Independent Research Fund Denmark (grant no. 6111245 00237), from Villum fonden (Grant No. 13158), from Haldor Topsøe A/S, and from Lundbeck 246 Foundation (grant no. R250-2017-1292). We thank Johannes R. Dethlefsen for assistance with the 
247 React-IR, Simone L. Zacho for assistance with TEM, and David Christensen for assistance with 248 XPS.

\section{References}

250 [1] Metal-Catalyzed Cross-Coupling Reactions and More; de Meijere, A., Brase, S., Oestreich, M., Eds.; Wiley-VCH:

251 Weinheim, Germany, 2014.

252 [2] Trnka, T. M.; Grubbs, R. H. Acc. Chem. Res. 2001, 34, 18-29

253 [3] Schneider, N.; Lowe, D. M.; Sayle, R. A.; Tarselli, M. A.; Landrum, G. A. J. Med. Chem. 2016, $594385-4402$.

254 [4] Wang, F.; Mielby, J.; Richter, F. H.; Wang, G.; Prieto, G.; Kasama, T.; Weidenthaler, C.; Bongard, H.-J.; Kegnæs, S.;

255 Fürstner, A.; Schüth F. Angew. Chem. Int. Ed. 2014, 53, 1-5.

256 [5] G. Stork, R. Terrell, J. Szmuszkovicz, J. Am. Chem. Soc. 1954, 76, 2029-2030.

257 [6] Reetz, M. T. Angew. Chem. Int. Ed. 1982, 21, 96-108.

258 [7] Trost, B. M.; Xu, J. J. Am. Chem. Soc. 2005, 127, 17180-17181.

259 [8] Nicewicz, D. A.; MacMillan, D. W. C. Science 2008, 322, 77-90.

260 [9] Mo, F.; Dong, G. Science 2014, 345, 68-72.

261 [10] Cano, R.; Zakarian, A.; McGlacken, G. P. Angew. Chem. Int. Ed. 2017, 56, 9278-9290.

262 [11] Anastas. P. T.; Kirchhoff, M. M. Acc. Chem. Res. 2002, 35, 686-694.

263 [12] Rothenberg, G. Catalysis: Concepts and Green Application, Wiley-VCH Verlag GmbH \& Co. KGaA, 2008 p. 2-9.

264 [13] Cho, C.; Kim, B.; Kim, T.-J.; Shim, S. J. Org. Chem. 2001, 66, 9020-9022.

265 [14] Cho, C. S.; Kim, B. T.; Kim, T.-J.; Shim, S. C. Tetrahedron Lett. 2002, 43, 7987-7989.

266 [15] Hamid, M. H. S. A.; Slatford, P. A.; Williams, J. M. J. Adv. Synth. Catal. 2007, 349, 1555-1575.

267 [16] Obora, Y. ACS Catal. 2014, 4, 3972-3982.

268 [17] Shimizu, K.-I. Catal. Sci. Technol. 2015, 5, 1412-1427.

269 [18] Huang, F.; Liu, Z.; Yu, Z. Angew. Chem. Int. Ed. 2016, 55, 862-875. 
[19] Corma, A.; Navas, J.; Sabater, M. J. Chem. Rev. 2018, 118, 1410-1459.

271 [20] Taguchi, K.; Nakagawa, H.; Hirabayashi, T.; Sakaguchi, S.; Ishii, Y. J. Am. Chem. Soc. 2004, 126, 72-73.

272 [21] Martínez, R.; Brand, G.; Ramón, D.; Yus, M. Tetrahedron Lett. 2005, 46, 3683-3686.

273 [22] Kuwahara, T.; Fukuyama, T.; Ruy, I. Org. Lett. 2012, 14, 4703-4705.

274 [23] Chan, L.; Poole, D.; Shen, D.; Healy, M.; Donohoe, T. Angew. Chem. Int. Ed. 2014, 53, 761-765.

275 [24] Ogawa, S.; Obora, Y. Chem Commun. 2014, 50, 2491-2493.

276

[25] Elangovan, S.; Sortais, J.-B.; Beller, M.; Darcel, C. Angew. Chem. Int. Ed. 2015, 54, 14483-14486.

277

[26] Peña-López, M.; Piehl, P.; Elangovan, S.; Neumann, H.; Beller, M. Angew. Chem. Int. Ed. 2016, 55, 14967-14971.

278

[27] Akhtar, W.; Cheong, C.; Frost, J.; Christensen, K.; Stevenson, N.; Donohoe, T. J. Am. Chem. Soc. 2017, 139,

279 $2577-2580$.

280

[28] Zhang, G.; Wu, J.; Zeng, H.; Zhang, S.; Yin, Z.; Zheng, S. Org. Lett. 2017, 19, 1080-1083.

281 [29] Chakraborty, S.; Daw, P.; David, Y. B.; Milstein, D. ACS Catal. 2018, 8, 10300-10305.

282 [30] Cao, X.-N.; Wan, X.-M.; Yang, F.-L.; Li, K.; Hao, X.-Q.; Shao, T.; Zhu, X.; Song, M.-P. J. Org. Chem. 2018, 83, $283 \quad 3657-3668$.

284 [31] Cho, C. J. Mol. Catal. A. 2005, 240, 55-60.

285 [32] Kwon, M.; Kim, N.; Seo, S.; Park, I.; Cheedrala, R.; Park, J. Angew. Chem. Int. Ed. 2005, 44, $6913-9515$.

286 [33] Yamada, Y.; Uozumi, Y. Org. Lett. 2006, 8, 1375-1378.

287 [34] Alonso, F.; Riente, P.; Yus, M. Acc. Chem. Res. 2011,44, 379-391.

288 [35] Cui, X.; Zhang, Y.; Shi, F.; Deng, Y. Chem. Eur. J. 2011, 17, 1021-1028.

289 [36] Chen, B. W. J.; Chng, L. L.; Yang, J.; Wei, Y.; Yang J.; Ying, J. Y. ChemCatChem, 2013, 5, $277-283$.

290 [37] Zhang, L.; Wang, A.; Wang, W.; Huang, Y.; Liu, X.; Miao, S.; Liu, J.; Zhang, T. ACS Catal. 2015, 5, 6563-6572.

291 [38] Hori, Y.; Suruga, C.; Akabayashi, Y.; Ishikawa, T.; Saito, M.; Myoda, T.; Toeda, K.; Maeda, Y.; Yoshida, Y. Eur J. 292 Org. Chem. 2017, 7295-7299.

293 [39] Reddy, C. B.; Bharti, R.; Kumar, S.; Das, P. ACS Sustainable Chem. Eng. 2017, 5, 9683-9691. 
294 [40] Jiang, L.; Guo, F.; Shi, Z.; Li, Y.; Hou, Z. ChemCatChem 2017, 9, 3827-3832.

295 [41] Siddiki, S. M. A. H; Touchy, A. S.; Jamil, M. A. R.; Toyao, T.; Shimizu, K.-I. ACS Catal. 2018, 8, 3091-3103.

296 [42] Laxmi, Y.; Bäckvall, J.-E. Chem. Commun. 2000, 0, 611-612.

297 [43] Kramer, S.; Hejjo, F.; Rasmussen, K. H., Kegnæs, S. ACS Catal. 2018, 8, 754-759.

298 [44] Kramer, S.; Mielby, J.; Buss, K.; Kasama, T.; Kegnæs, S. ChemCatChem 2017, 9, 2930-2934.

299 [45] Jaska, C. A.; Manners, I. J. Am. Chem. Soc. 2004, 126, 9776-9785.

300 [46] Mamidala, R.; Samser, S.; Sharma, N.; Lourderaj, U.; Venkatasubbaiah, K. Organometallics 2017, 36, 3343-3351.

301 [47] Brun, M.; Berthet, A.; Bertolini, J. C. J. Electron Spectrosc. 1999, 104, 55-60.

302 [48] Blackmond, D. Angew. Chem. Int. Ed. 2005, 44, 4302-4320.

303 [49] Bures, J. Angew. Chem. Int. Ed. 2016, 55, 16084-16087. 